\title{
BINDER-AGGREGATE ADHESION AND RESISTANCE TO PERMANENT \\ DEFORMATION OF BITUMEN-EMULSION-STABILIZED MATERIALS MADE WITH CONSTRUCTION AND DEMOLITION WASTE AGGREGATES
}

\author{
B. Gómez-Meijide ${ }^{a, *}$, I. Pérez ${ }^{b}$ \\ ${ }^{a}$ Nottingham Transportation Engineering Centre (NTEC), Department of Civil Engineering, University of \\ Nottingham, Nottingham, UK, NG7 2RD \\ ${ }^{b}$ Universidade da Coruña. E.T.S.I. Caminos, Canales y Puertos, Campus de Elviña s/n, 15071. A Coruña, Spain \\ *Corresponding author. Tel.: +44 (0)115 951 3900. Fax: +44(0)1159513909 \\ E-mail addresses: breixo.gomez.meijide@nottingham.ac.uk(B.Gómez.Meijide),iperez@udc.es (I.Pérez)
}

\begin{abstract}
Bitumen-stabilized materials with emulsion (BSM-E) are gaining increasing importance within the scope of road pavement engineering and the fight against climate change. Both environmental and economic aspects of BSM-E can be further improved by substituting the natural aggregates (NA) with recycled construction and demolition waste aggregates (CDWA). The objective of the present paper is to analyze how such substitution affects the two critical properties that mostly define the durability and long-term performance of BSM-E: resistance to stripping and resistance to permanent deformation. The stripping phenomena were analyzed in terms of binder-aggregate affinity through the Rolling Bottle Test and Boiling Water Test. The results showed that the weak mortar that attached to the aggregate surface produced poorer binder-aggregate affinity when the samples were subjected to mechanical agitation. However, the recycled aggregates did not affect the affinity at high temperatures and improved the resistance to permanent deformation, leading to failure of the material after many loading cycles.
\end{abstract}

\section{Keywords}

Bitumen-stabilized materials with emulsion; construction and demolition waste; recycled aggregates; binder - aggregate adhesion; resistance to permanent deformation; sustainable materials 


\section{Introduction}

Bitumen-stabilized materials with emulsion (BSM-E $\left.{ }^{1}\right)$ are the result of mixing aggregates, asphalt emulsion and water. The use of asphalt emulsion instead of bitumen enables the mix to be blended, laid and compacted at room temperature, reducing economic and environmental costs; thus, it is gaining popularity within the scope of the fight against climate change in civil engineering. These materials once were considered inferior to hot mix asphalt $\left(\mathrm{HMA}^{2}\right)$ owing to their high air void content after compaction and weak early life strength; however, their current uses cover a great range of applications in addition to the conventional ones, including surface treatments and reinstatement work on low-traffic roads and walkways (Nageim et al., 2012; Read and Whiteoak and Whiteoak, 2003; HAUC, 1992; James, 2006).

Both environmental and economic aspects of BSM-E can be improved by substituting the natural aggregates $\left(\mathrm{NA}^{3}\right)$ with recycled construction and demolition waste aggregates $\left(\mathrm{CDWA}^{4}\right)$, an approach that is currently being applied, with successful results, to other kinds of infrastructure materials, such as road bases (Xuan et al., 2015), concrete (Bravo et al., 2016; Rodríguez et al., 2016), mortar (Ledesma et al., 2015; Saiz Martínez et al., 2016) or geosynthetic reinforced structures (Vieira et al., 2016). However, the great heterogeneity of this type of aggregate, especially in terms of their composition, makes it very difficult to predict how they will affect the properties of asphalt mixtures. In the limited literature published on HMA with CDWA, certain common trends were found, such as higher air void content but lower content of voids filled with bitumen (Shen and Du, 2005; Paranavithana and Mohajerani, 2006; Wong et al., 2007; Pérez et al., 2010); lower densities (Huang et al., 2002; Li, 2004; Paranavithana and Mohajerani, 2006; Pérez et al., 2007; Melbouci, 2009; Mills-Beale and You, 2010; Gokce et al., 2011); higher optimal binder content (Paranavithana and Mohajerani, 2006; Wong et al., 2007; Pérez et al., 2010); higher resistance to cracking at low temperature (Mills-Beale and You, 2010); and lower resistance to water

\footnotetext{
${ }^{1}$ BSM-E: Bitumen Stabilized Materials with Emulsion

2 HMA: Hot Mix Asphalt

${ }^{3}$ NA: Natural Aggregates

${ }^{4}$ CDWA: Construction and Demolition Waste Aggregates
} 
damage and stripping phenomena (Shen and Du, 2005; Paranavithana and Mohajerani, 2006; Pasandín and Pérez, 2013, 2014c; Pérez et al., 2007, 2010, 2012a, 2012b). In addition, contradictory results were found on other properties, such as indirect tensile strength and stiffness (Shen and Du, 2005; Paranavithana and Mohajerani, 2006; Mills-Beale and You, 2010; Chen et al., 2011; Pasandín and Pérez, 2013, 2014c), resistance to permanent deformation (Shen and Du, 2005; Paranavithana and Mohajerani, 2006; Wong et al., 2007; Mills-Beale and You 2010; Chen et al., 2011a; Pérez et al., 2012; Bhusal and Wen 2013; Pasandín and Pérez, 2013, 2014b, 2014c), and fatigue (Pérez et al., 2010a; Chen et al., 2011a, 2011b; Chen et al.; Bhusal and Wen, 2013; Pasandín and Pérez, 2013, 2014c), without sufficient clarity regarding whether the incorporation of CDWA produce positive or negative effects on these properties. Regarding BSM-E with CDWA, the published literature is even shorter, but works including Thanaya (2003; 2010); Gómez-Meijide and Pérez (2014a, 2014b, 2015); and Gómez-Meijide et al. (2015a, 2015b) confirmed the abovementioned trends and improvements in some mechanical properties, such as compression strength, indirect tensile strength, stiffness and stability to temperature variations. Some weaknesses were also found (especially the behavior at early curing stages), but none of the previous publications studied the two phenomena that mostly define the durability and long-term performance of BSM-E: the resistance to stripping and the resistance to permanent deformations (it must be noted that owing to the higher flexibility of this type of mixture, fatigue is not usually the critical failure mechanism). The objective of the present study is precisely to determine, for BSM-E, how the addition of CDWA affects these two critical properties.

\section{Materials and method}

\subsection{Materials and production of specimens}

The samples were made with two different sources of aggregates. On the one hand, aggregate from construction and demolition waste was recycled, mainly composed of concrete, mortar and stone with a certain proportion of impurities including ceramics, metal pieces, gypsum, plastics and glass (Table 1). On the other hand, a hornfels, a common metamorphic siliceous NA extracted from a local quarry in Ourense (Spain), was used to produce the control mixes. In 
Table 2, the main characteristics of both aggregates can be seen, of which the high water absorption and low specific gravity of CDWA are especially remarkable.

Table 1. Components of recycled aggregate (\% of total dry weight)

\begin{tabular}{lcc}
\hline Material & $\begin{array}{c}\text { \% In Coarse } \\
\text { Aggregate } \\
\mathbf{( 1 2 / 2 4} \mathbf{~ m m})\end{array}$ & $\begin{array}{c}\text { \% In Medium } \\
\text { Aggregate } \\
\mathbf{( 6 / 1 2} \mathbf{~ m m})\end{array}$ \\
\hline Concrete and mortar & $70 \%$ & $55 \%$ \\
Natural aggregates & $25 \%$ & $40 \%$ \\
Ceramics and masonry materials & $3.7 \%$ & $4.1 \%$ \\
Concrete with metal pieces & $1.121 \%$ & $<0.001 \%$ \\
Concrete with textile fibers & $0.146 \%$ & $0.042 \%$ \\
Plaster/gypsum & $0.103 \%$ & $0.012 \%$ \\
Other materials (metal, paper, plastic, glass) & $<0.1 \%$ & $0.1 \%$ \\
\hline
\end{tabular}

Table 2. Characterization of recycled and natural aggregates

\begin{tabular}{lcc}
\hline Property & $\begin{array}{c}\text { Recycled } \\
\text { aggregate }\end{array}$ & $\begin{array}{c}\text { Natural } \\
\text { aggregate }\end{array}$ \\
\hline Flakiness Index (UNE EN 933-3) & $4.5 \%$ & $19.8 \%$ \\
Crushed particles (UNE EN 933-5) & $89 \%$ & $94 \%$ \\
Sand equivalent (UNE EN 933-8) & 77 & 78 \\
Los Angeles coefficient (UNE EN 1097-2) & 38 & 14 \\
Bulk specific gravity (UNE EN 1097-6) & $2.64 \mathrm{t} / \mathrm{m}^{3}$ & $2.78 \mathrm{t} / \mathrm{m}^{3}$ \\
Dry specific gravity (UNE EN 1097-6) & $2.23 \mathrm{t} / \mathrm{m}^{3}$ & $2.74 \mathrm{t} / \mathrm{m}^{3}$ \\
SSD specific gravity (UNE EN 1097-6) & $2.39 \mathrm{t} / \mathrm{m}^{3}$ & $2.75 \mathrm{t} / \mathrm{m}^{3}$ \\
Absorption (UNE EN 1097-6) & $7.0 \%$ & $0.5 \%$ \\
\hline
\end{tabular}

The selected binder for all samples was a cationic slow-setting bitumen emulsion (60\% bitumen content) with 100 pen grade base bitumen.

Following the recommendations of the Spanish Technical Association of Bituminous Emulsions (ATEB) (ATEB, 2015), all samples were made with the same gradation, corresponding to a grave emulsion GE1. The fine part of the gradation curve was adjusted to the lower limit because of the trend observed in CDWA to increase the amount of fine particles after the mixing and compaction processes (Figure 1).

For the rutting tests, the mixtures were composed according to Standard NLT-161, derived from the French Duriez test (NF P98-251) and widely used for BSM-E. Thus, 101.6-mm height $\times$ 101.6-mm diameter cylindrical specimens were obtained after applying a static compaction of 1 MPa for $1 \mathrm{~min}$ (preload) followed by $21 \mathrm{MPa}$ for $2 \mathrm{~min}$. The samples were then cut with a radial saw blade, maintaining the diameter in $101.6 \mathrm{~mm}$ but reducing the height to $50 \mathrm{~mm}$. 
Because rutting is a long-term phenomenon, which especially occurs after many cycles, the BSM-E samples were fully cured until the mass remained constant. With this aim, and as specified by ATEB (ATEB, 2015), a 3-day curing time was applied in an oven at $50^{\circ} \mathrm{C}$.

However, after the process, it was found that the weight was still not constant. Therefore, and to avoid premature aging of the binder, the samples were stored at room temperature $\left(20 \pm 2^{\circ} \mathrm{C}\right)$ for 18 months.

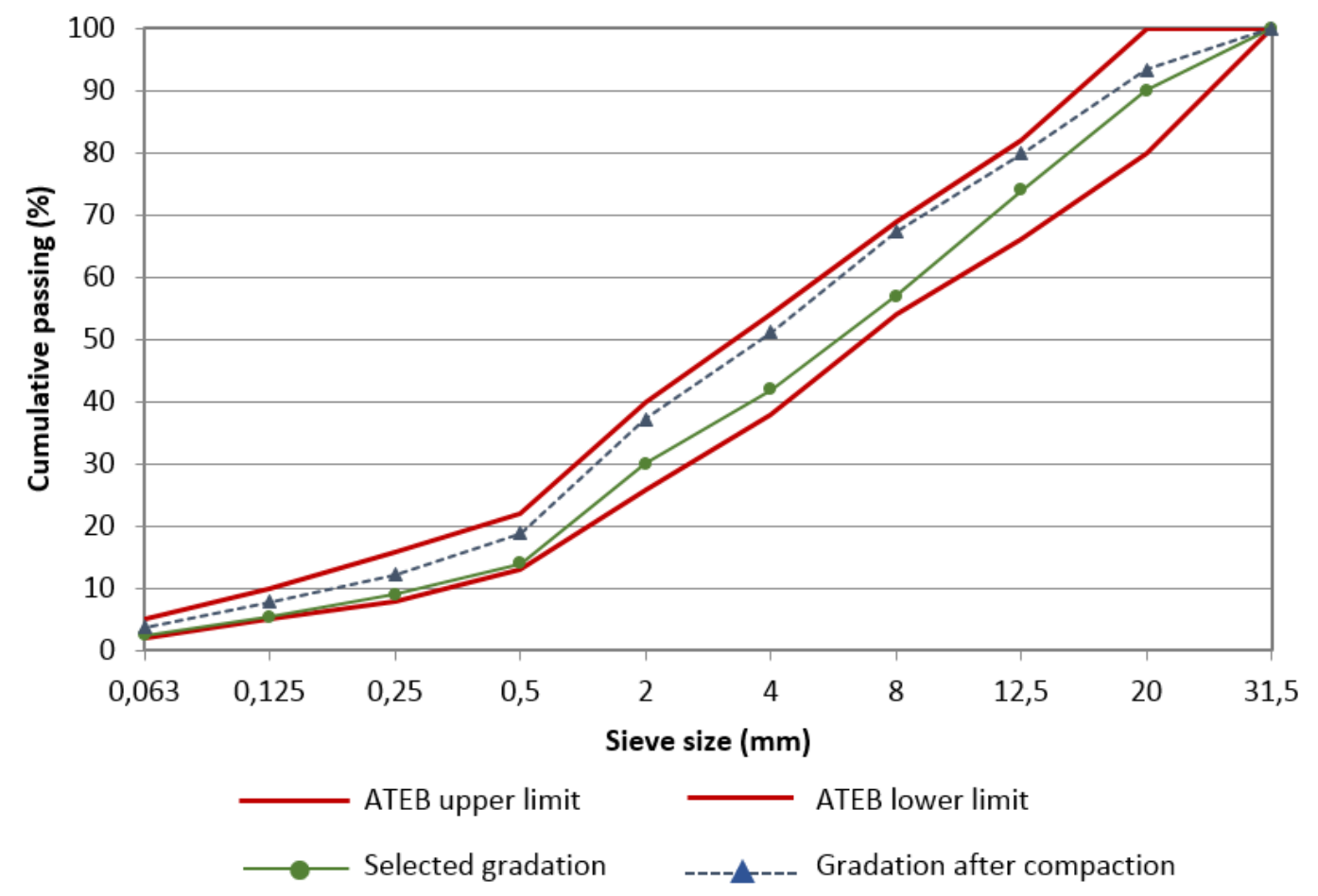

Figure 1. Aggregate gradation of CDWA before and after compaction compared with ATEB recommendations

\subsection{Testing program}

\subsubsection{Aggregate-binder affinity}

Aggregate-binder affinity is an indicator of the susceptibility of a certain mix to stripping phenomena. This susceptibility, as treated in the present paper, is an indirect measure of the capacity of a given binder to adhere to different aggregates used for the present investigation. For this purpose, two different methods were used:

a) First, the rolling bottle test was applied. In this test, the aggregate-binder bond is assessed by means of visual inspection of the aggregate coating grade, once the loose mix has been 
subjected to mechanical agitation in the presence of water. This test was performed according to Standard UNE-EN 12697-11.

b) The second method was the boiling water test, which also involves the visual inspection of the coating grade of aggregates but only after having immersed the loose mix in boiling water under controlled conditions. This test is described in the American standard ASTM D 3625. Although both tests fix a given amount of binder to be added to the mix, the present investigation went beyond this point, repeating the procedures with different binder contents (given a fixed water content) and with different water contents (given a binder content).

Furthermore, to assess how the curing processes may affect the aggregate-binder adhesion, the tests were repeated with samples cured for 0 (control mixes), 3 and 7 days. A curing time of 3 days was selected because it is a common process included in a great deal of standards and investigations on BSM-E (ATEB, 2015). In addition, 7 days was considered as enough time to completely develop the curing of the mixes. The whole range of tests is summarized in Table 3.

Table 3. Summary of mixes with different sources of aggregate (CDWA and NA), water and bitumen contents and after being cured for different periods of time, used for both the Rolling Bottle Test and Boiling Water Test

\begin{tabular}{|c|c|c|c|c|c|}
\hline \multicolumn{3}{|c|}{ CDWA } & \multicolumn{3}{|c|}{ NA } \\
\hline Bitumen & Water & Curing & Bitumen & Water & Curing \\
\hline $5 \%$ & $\begin{array}{c}9 \% \\
12 \% \\
15 \% \\
18 \% \\
\end{array}$ & 3 days & $4 \%$ & $\begin{array}{c}3 \% \\
6 \% \\
9 \% \\
12 \% \\
\end{array}$ & 3 days \\
\hline $\begin{array}{c}3 \% \\
4 \% \\
5 \% \\
- \\
\end{array}$ & $15 \%$ & 3 days & $\begin{array}{l}2 \% \\
3 \% \\
4 \% \\
5 \% \\
\end{array}$ & $3 \%$ & 3 days \\
\hline $5 \%$ & $15 \%$ & $\begin{array}{l}0 \text { days } \\
3 \text { days } \\
7 \text { days }\end{array}$ & $4 \%$ & $3 \%$ & $\begin{array}{l}0 \text { days } \\
3 \text { days } \\
7 \text { days }\end{array}$ \\
\hline
\end{tabular}

\subsubsection{Rolling bottle test}

Standard UNE-EN 12697-11, specific for HMA, was modified in this investigation to test BSM-E. Thus, $510 \pm 2 \mathrm{~g}$ of dry aggregate of the fraction $8 / 11.2 \mathrm{~mm}$ were mixed with the proper binder amount (although the standard specifies 3\% binder over mix weight, this test was 
repeated with different residual bitumen contents; owing to the high absorption of CDWA, it was observed that $3 \%$ was insufficient to completely coat the particles). In this line, it was also unnecessary to heat the materials, so the cooling step could be removed from the process specified in the mentioned standard. However, the aggregate particles were spread over a metal plate for $24 \mathrm{~h}$, and a certain curing process was applied by introducing the samples into the oven at $50^{\circ} \mathrm{C}$ for 0 (control mixes), 3 or 7 days.

The samples were then divided into three $150 \pm 2 \mathrm{~g}$ subsamples and introduced into standard bottles filled with distilled water at $5^{\circ} \mathrm{C}$. Together with the loose mix and the water, a standard glass rod was introduced, and the bottles were hermetically sealed with a screw plug.

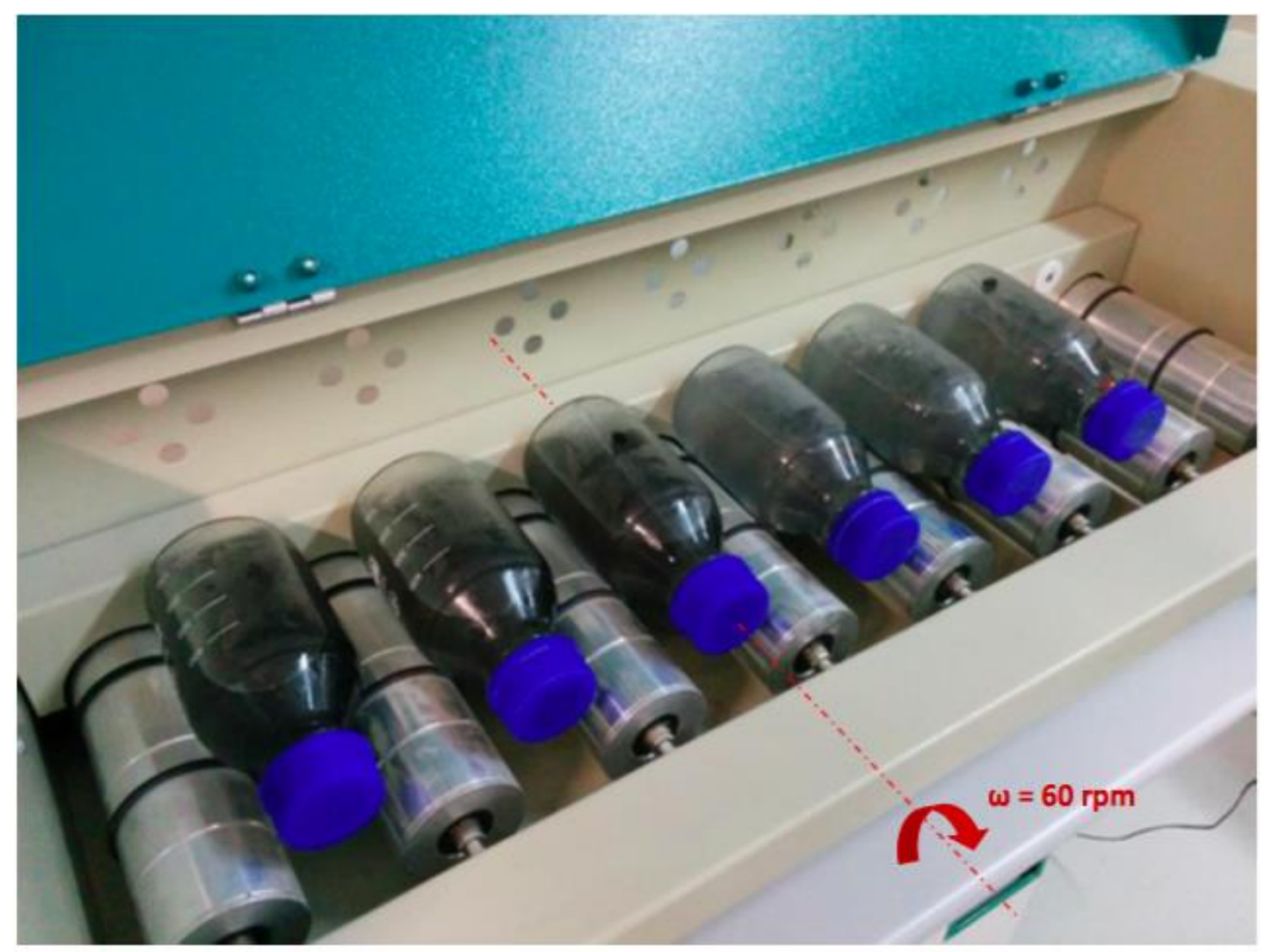

Figure 2. Arrangement of two different samples (6 subsamples) during the rolling bottle test

The bottles were laid and rotated at a speed of $60 \mathrm{rpm}$ (Figure 2). After $6 \mathrm{~h}$, the particles were extracted over a glass plate, and the coating grade was visually determined, rounding to the nearest $\pm 5 \%$. The samples were then introduced again into the bottles, and the test was continued for $24 \mathrm{~h}$, repeating the observations as in the first case. The results are calculated as the average value of the 3 subsamples, according to 2 different observers. 
During the mixing process, the mixing time needed for each mixture to reach the complete coating (active affinity) was also observed.

\subsubsection{Boiling water test}

As described for the previous test, in this case, Standard ASTM 3625 was adapted for BSM-E, with the materials not heated during the mix but later, during the curing process. Two-hundredfifty-gram samples of dry aggregate of the $8 / 12 \mathrm{~mm}$ fraction were mixed with different water and bitumen contents (the same contents as for the previous tests) until complete and uniform coating of the particles was reached.

Afterwards, the particles were spread over a metal plate and left for $24 \mathrm{~h}$ before being subjected to a curing process in an oven at $50^{\circ} \mathrm{C}$ for 0,3 and 7 days (as in the previous test). The loose mix was then heated between $85^{\circ} \mathrm{C}$ and the boiling temperature of water and introduced into a vat with boiling water for $10 \mathrm{~min}$. After this time, the unattached bitumen particles and the water were removed, and the samples were spread again at room temperature for $24 \mathrm{~h}$.

Finally, visual inspections were carried out by 2 different observers, and the coating grade was determined as the average value of both.

\subsubsection{Resistance to permanent deformation}

To assess how these results affect the resistance to permanent deformation, a large series of samples with different combinations of water/emulsion contents were subjected to the Repeated Load Axial Test according to Standard BSi DD 226:1996 (BSi, 1996) (Figure 3). Thus, cylindrical 101.6-mm diameter $\times 50$-mm height samples were lubricated with a mix of silicone grease and graphite powder on their flat sides, slowly heated to the test temperature $\left(30^{\circ} \mathrm{C}\right)$ and subjected to a static conditioning load of $10 \mathrm{kPa}$ for $600 \pm 6 \mathrm{~s}$. The samples were then subjected to a series of $100 \pm 2 \mathrm{kPa}$ dynamic loads at a constant temperature. Each load pulse involved a $1 \mathrm{~s}$ load followed by a $1 \mathrm{~s}$ rest period where no load was applied. Although the standard requires the application of only 1800 load cycles, in the present investigation, the tests were prolonged to 5000 cycles to obtain clearer creep data and curves. 

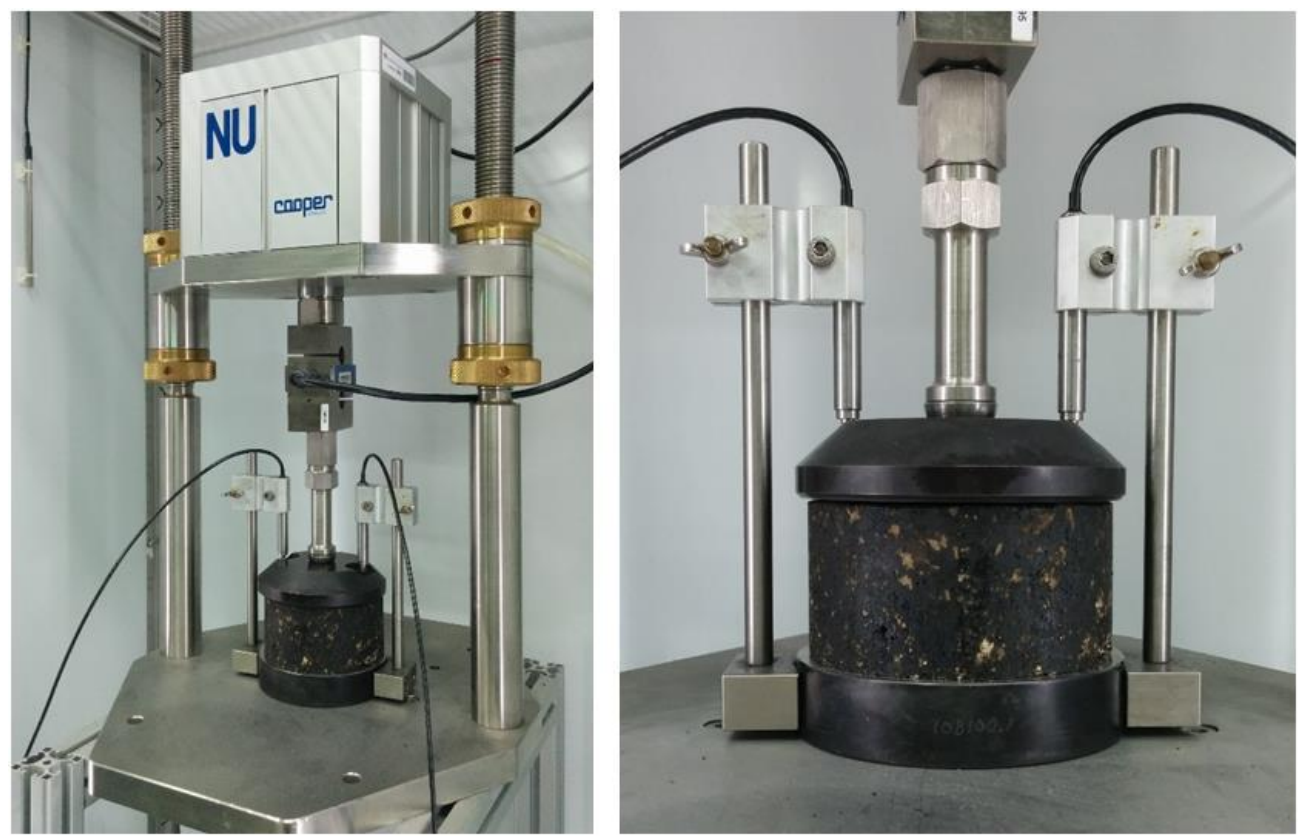

Figure 3. Arrangement of repeated load axial test according to Standard BSi DD 226:1996

(BSi, 1996)

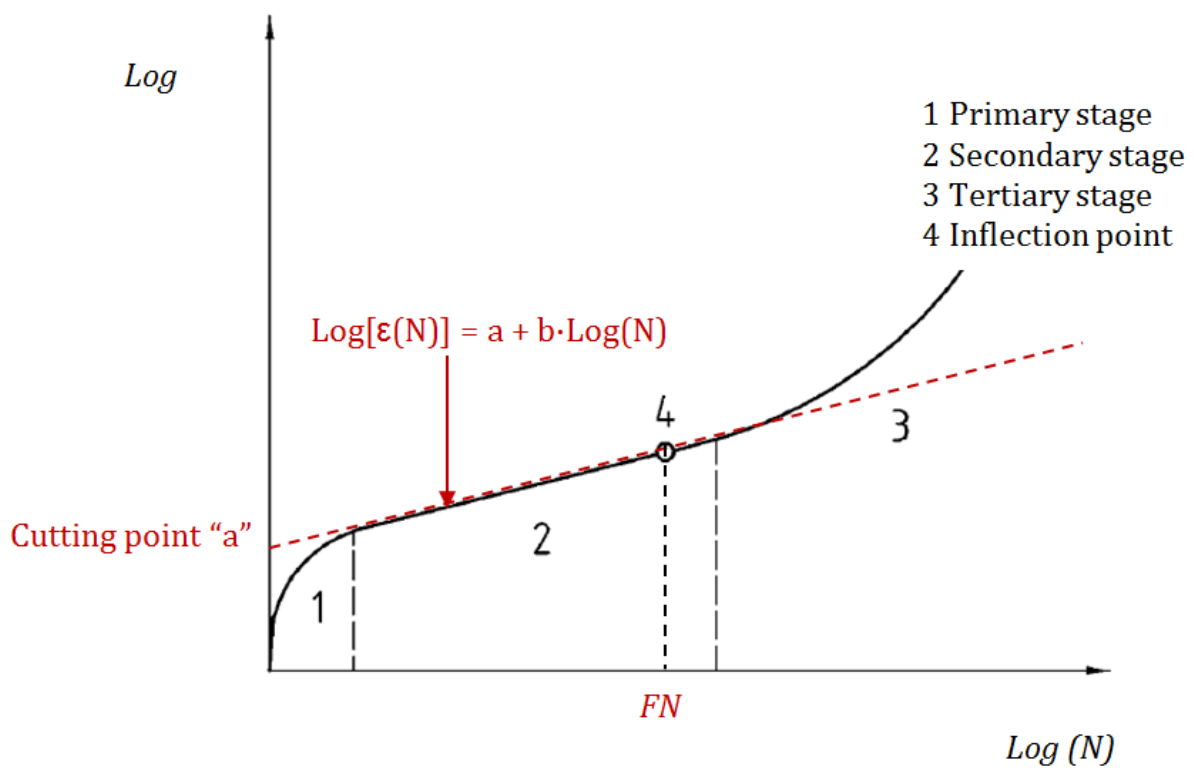

Figure 4. Typical creep curve of axial deformation related to the number of load cycles (from Norma UNE-EN 12697-25)

The samples were produced according to Standard NLT-161, which is widely used for BSM-E in Spain and whose compaction method involves the application of a static load of $21 \mathrm{MPa}$ for 2 min. Finally, the samples were fully cured in an oven for 3 days at $50^{\circ} \mathrm{C}$ (according to ATEB recommendations) and left at room temperature until reaching a constant weight. 
For each tested mix, a creep curve (similar to the scheme shown in Figure 4) was obtained. As seen, these curves are composed of three different stages:

- Primary stage, where the slope decreases with increasing number of applied load cycles. In this stage, the void content decreases, producing a densification phenomenon, in contrast to the plastic deformation that typically occurs during the tertiary stage.

- Secondary stage: along this stage, the creep curve is similar to a straight line with a constant slope (logarithmic scale). The greater the slope of the tangent line ("b") and the cutting point of this with the vertical axis ("a"), the greater the rutting potential of the mix. In this stage, an inflection point can also be seen, from which point the slope of the creep curve increases again with increasing number of load cycles. The number of cycles at which this occurs, which is normally called the Flow Number (FN), is the minimum slope point of the curve (Gul, 2008) and is considered as a critical point from which the sample starts to fail (Santagata et al., 2007). - Tertiary stage: In this stage, plastic flow occurs, and binder and aggregates move without producing a change in the volume. This phenomenon produces curves whose slopes increase with increasing number of cycles until the final collapse of the specimens.

In the present investigation, the parameters used to compare the mixes were, in addition to the point "a" and the slope " $\mathrm{b}$ ", the initial strain after conditioning $\left(\varepsilon_{0}\right)$, the final strain after 5000 cycles $\left(\varepsilon_{5000}\right)$, and the Flow Number.

\section{Results}

\subsection{Binder-aggregate affinity}

\subsubsection{Rolling bottle test}

The results of rolling bottle test are shown in Table 4, Figures 5 to 7 . First, it can be seen that the coating grade is higher when NA is used. Thus, the bond between binder and CDWA is weaker than with NA. Logically, by increasing the binder content, higher coating grades can be achieved with CDWA (i.e., increasing from $63 \%$ with $3 \%$ bitumen content at $24 \mathrm{~h}$ to $73 \%$ with $5 \%$ ); but even so, these values are still far from those obtained with NA, which remained in most cases between $95 \%$ and $100 \%$. As an exception, it can be seen how 5\% bitumen content 
performed worse ( $78 \%$ after $6 \mathrm{~h}$ and $59 \%$ after $24 \mathrm{~h}$ ); this is possibly due to an excessively thick film coating the aggregates, which can be easily detached.

Table 4. Results of rolling bottle test for mixes with CDWA and NA and different water and bitumen contents and curing times

\begin{tabular}{|c|c|c|c|c|c|c|}
\hline \multirow{2}{*}{$\begin{array}{c}\text { Aggregat } \\
\text { e }\end{array}$} & \multirow{2}{*}{$\begin{array}{l}\text { Binder } \\
\text { content }\end{array}$} & \multirow{2}{*}{$\begin{array}{l}\text { Water } \\
\text { content }\end{array}$} & \multirow{2}{*}{$\begin{array}{c}\text { Curing } \\
\text { time }\end{array}$} & \multicolumn{2}{|c|}{ Coating grade } & \multirow{2}{*}{$\begin{array}{c}\text { Coating } \\
\text { time } \\
(\mathrm{s})\end{array}$} \\
\hline & & & & $6 \mathrm{~h}$ & $24 \mathrm{~h}$ & \\
\hline \multirow{10}{*}{ Recycled } & \multirow{4}{*}{$5 \%$} & $9 \%$ & \multirow{4}{*}{3 days } & $73 \%$ & $63 \%$ & 27 \\
\hline & & $12 \%$ & & $95 \%$ & $90 \%$ & 25 \\
\hline & & $15 \%$ & & $91 \%$ & $78 \%$ & 17 \\
\hline & & $18 \%$ & & $92 \%$ & $83 \%$ & 18 \\
\hline & $3 \%$ & \multirow{3}{*}{$15 \%$} & \multirow{3}{*}{3 days } & $78 \%$ & $63 \%$ & 27 \\
\hline & $4 \%$ & & & $89 \%$ & $73 \%$ & 14 \\
\hline & $5 \%$ & & & $91 \%$ & $78 \%$ & 17 \\
\hline & \multirow{3}{*}{$5 \%$} & \multirow{3}{*}{$15 \%$} & 0 days & $83 \%$ & $71 \%$ & 16 \\
\hline & & & 3 days & $91 \%$ & $78 \%$ & 17 \\
\hline & & & 7 days & $89 \%$ & $73 \%$ & 15 \\
\hline \multirow{11}{*}{ Natural } & \multirow{4}{*}{$4 \%$} & $3 \%$ & \multirow{4}{*}{3 days } & $100 \%$ & $100 \%$ & 56 \\
\hline & & $6 \%$ & & $100 \%$ & $95 \%$ & 9 \\
\hline & & $9 \%$ & & $100 \%$ & $100 \%$ & 17 \\
\hline & & $12 \%$ & & $100 \%$ & $100 \%$ & 10 \\
\hline & $2 \%$ & \multirow{4}{*}{$3 \%$} & \multirow{4}{*}{3 days } & $100 \%$ & $97 \%$ & 53 \\
\hline & $3 \%$ & & & $100 \%$ & $100 \%$ & 35 \\
\hline & $4 \%$ & & & $100 \%$ & $100 \%$ & 56 \\
\hline & $5 \%$ & & & $78 \%$ & $59 \%$ & 60 \\
\hline & \multirow{3}{*}{$4 \%$} & \multirow{3}{*}{$3 \%$} & 0 days & $100 \%$ & $94 \%$ & 20 \\
\hline & & & 3 days & $100 \%$ & $100 \%$ & 56 \\
\hline & & & 7 days & $100 \%$ & $100 \%$ & 90 \\
\hline
\end{tabular}

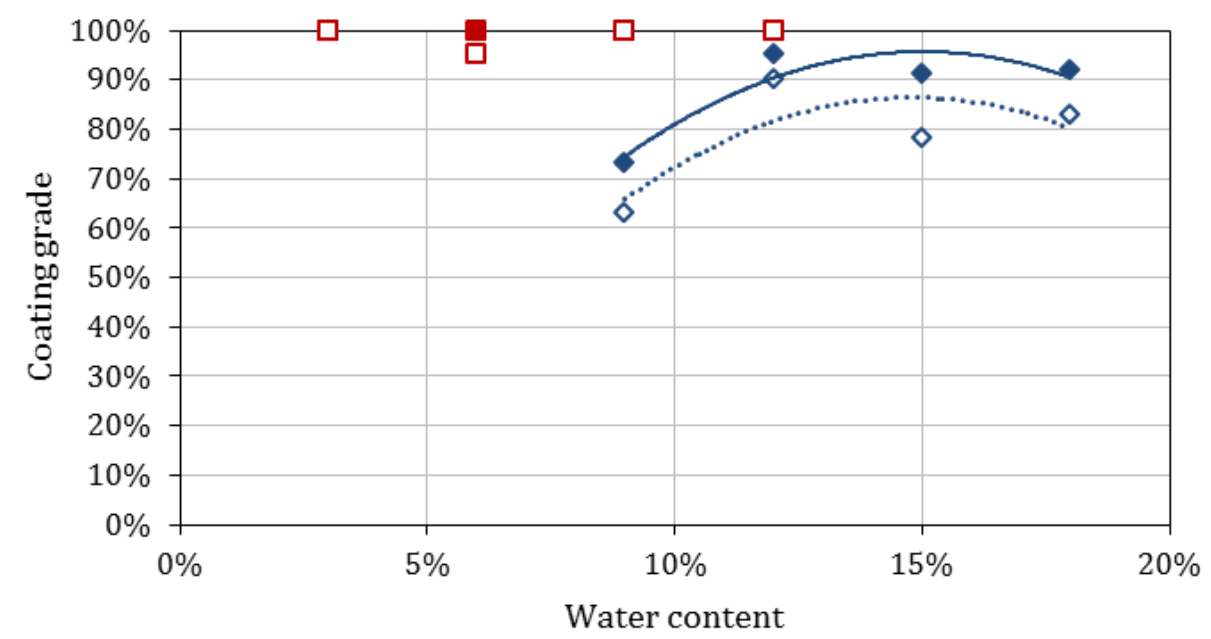

Recycled 6h ORecycled 24h $\quad$ Natural 6h $\quad \square$ Natural 24h

Figure 5. Relationship between coating grade after $6 \mathrm{~h}$ and $24 \mathrm{~h}$ tests and water content 


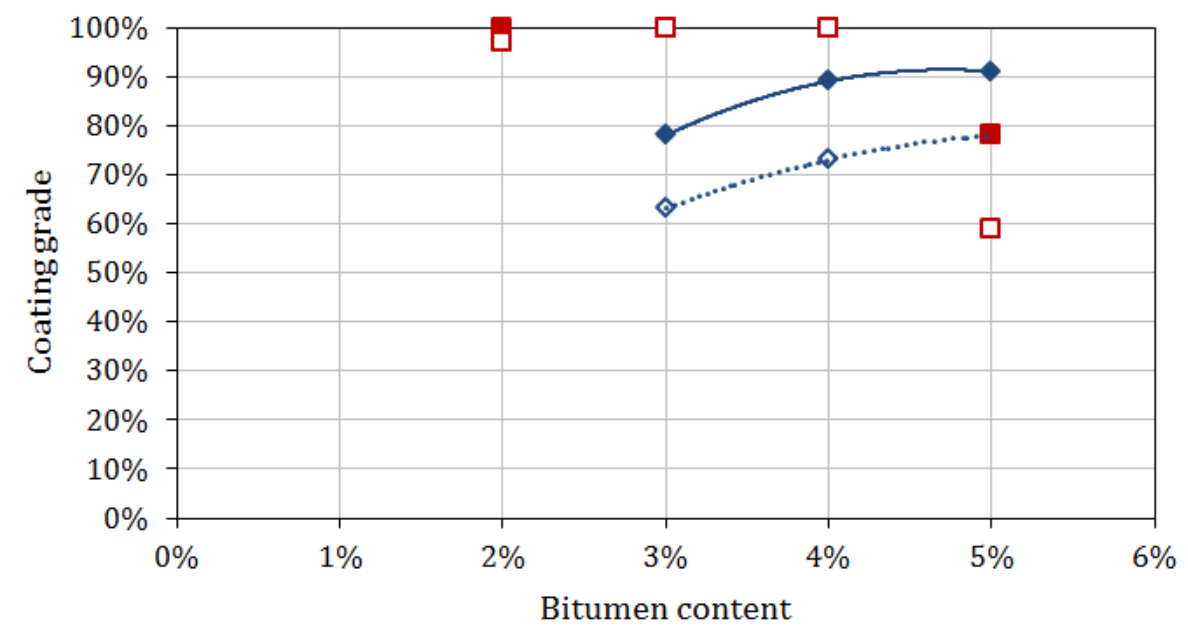

Recycled 6h ORecycled 24h $\quad$ Natural 6h $\square$ Natural 24h

Figure 6. Relationship between coating grade after $6 \mathrm{~h}$ and $24 \mathrm{~h}$ tests and bitumen content

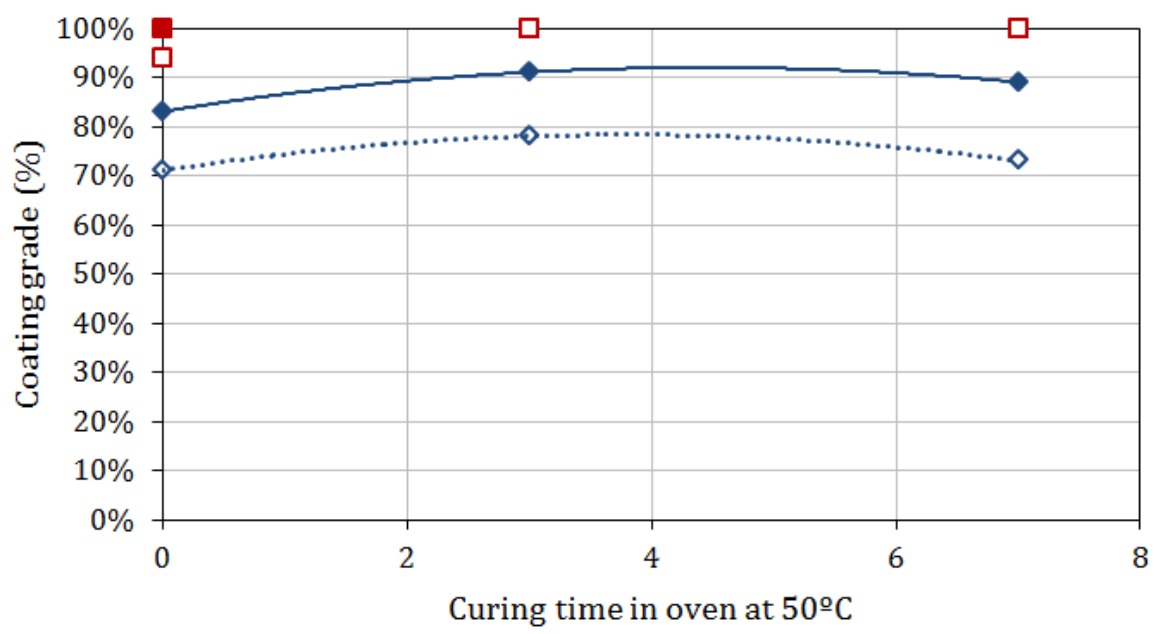

Recycled 6h ORecycled 24h $\quad$ Natural $6 \mathrm{~h} \quad \square$ Natural 24h

Figure 7. Relationship between coating grade after $6 \mathrm{~h}$ and $24 \mathrm{~h}$ tests and curing time

However, increasing the water content also helped mixes with CDWA reduce the mixing time needed to obtain complete coating of the aggregate. Moreover, the coating grades at the end of the tests did not seem to significantly improve.

Finally, the curing time had a slight influence on the coating grades, although it is noticeable that when the mixes were tested without the application of any curing process $(0 \mathrm{~h})$, the results were poorer than after 3 and 7 days in the oven at $50^{\circ} \mathrm{C}$. In the case of mixes with CDWA, the mixes cured for 7 days produced results slightly poorer than the mixes cured for 3 days, which 
might be a symptom of the aging of the binder and the loss of volatile components in the oven. However, the same evidence was not found in mixes with NA.

\subsubsection{Boiling water test}

The results of this test are shown in Table 5. As can be observed, all results are higher than the threshold of $85-90 \%$, which, according to Kiggundu and Roberts (1988), is the minimum that can ensure good adhesion between binder and aggregates in HMA. The only exception to this was the mix with CDWA, $5 \%$ bitumen and $9 \%$ water. The low water content, together with excessively high bitumen content, led to a thick and stiff film easily detachable from the aggregate surface.

The results are generally higher than those obtained with the rolling water test. In mixes with NA, the results continue to be near $100 \%$, but in this case, the mixes with CDWA are also near these values.

With this test, it is impossible to obtain a clear relationship between the coating grade and the water and bitumen contents because all results were generally more than satisfactory. Nevertheless, the uncured mixes and the mixes cured for 7 days again produced binderaggregate affinities slightly lower than that cured for 3 days. This is related, as in the previous case, to the presence of interstitial water within the uncured mixes and to the aging and stiffening of the binder cured for 7 days.

In this case, it is especially noticeable that the results exceeded the values obtained by other authors (Pasandín and Pérez, 2014; Pasandín et al., 2015) with HMA and CDWA, who reached coating grades of only $80 \%$ after the incorporation of cement as filler. By means of different pretreatments, they obtained higher coating grades of approximately $90-95 \%$, values generally exceeded in this investigation, with $100 \%$ of CDWA and without using any sort of additive or pretreatment.

As in the previous case, the bitumen content does not affect the coating time in a significant way. However, by increasing the water content, it was possible to obtain clear reductions (for instance, in mixes with CDWA, this time was reduced from $57 \mathrm{~s}$ with $9 \%$ water content to $9 \mathrm{~s}$ with $18 \%)$. 
Table 5. Results of boiling water test for mixes with CDWA and NA and different water and bitumen contents and curing times

\begin{tabular}{|c|c|c|c|c|c|c|}
\hline \multirow{2}{*}{ Aggregate } & \multirow{2}{*}{$\begin{array}{l}\text { Binder } \\
\text { content }\end{array}$} & \multirow{2}{*}{$\begin{array}{l}\text { Water } \\
\text { content }\end{array}$} & \multirow{2}{*}{$\begin{array}{c}\text { Curing } \\
\text { time }\end{array}$} & \multicolumn{2}{|c|}{ Coating grade } & \multirow{2}{*}{$\begin{array}{l}\text { Coating } \\
\text { time } \\
\text { (s) }\end{array}$} \\
\hline & & & & $6 \mathrm{~h}$ & $24 \mathrm{~h}$ & \\
\hline \multirow{10}{*}{ Recycled } & \multirow{4}{*}{$5 \%$} & $9 \%$ & \multirow{4}{*}{3 days } & $70 \%$ & $60 \%$ & 57 \\
\hline & & $12 \%$ & & $95 \%$ & $95 \%$ & 19 \\
\hline & & $15 \%$ & & $95 \%$ & $95 \%$ & 22 \\
\hline & & $18 \%$ & & $95 \%$ & $95 \%$ & 9 \\
\hline & $3 \%$ & \multirow{3}{*}{$15 \%$} & \multirow{3}{*}{3 days } & $95 \%$ & $95 \%$ & 19 \\
\hline & $4 \%$ & & & $90 \%$ & $90 \%$ & 19 \\
\hline & $5 \%$ & & & $95 \%$ & $95 \%$ & 22 \\
\hline & \multirow{3}{*}{$5 \%$} & \multirow{3}{*}{$15 \%$} & 0 days & $95 \%$ & $95 \%$ & 7 \\
\hline & & & 3 days & $95 \%$ & $95 \%$ & 22 \\
\hline & & & 7 days & $90 \%$ & $90 \%$ & 12 \\
\hline \multirow{11}{*}{ Natural } & \multirow{4}{*}{$4 \%$} & $3 \%$ & \multirow{4}{*}{3 days } & $100 \%$ & $100 \%$ & 21 \\
\hline & & $6 \%$ & & $100 \%$ & $100 \%$ & 25 \\
\hline & & $9 \%$ & & $100 \%$ & $100 \%$ & 19 \\
\hline & & $12 \%$ & & $100 \%$ & $100 \%$ & 15 \\
\hline & $2 \%$ & \multirow{4}{*}{$3 \%$} & \multirow{4}{*}{3 days } & $100 \%$ & $100 \%$ & 20 \\
\hline & $3 \%$ & & & $100 \%$ & $100 \%$ & 31 \\
\hline & $4 \%$ & & & $100 \%$ & $100 \%$ & 21 \\
\hline & $5 \%$ & & & $100 \%$ & $100 \%$ & 41 \\
\hline & \multirow{3}{*}{$4 \%$} & \multirow{3}{*}{$3 \%$} & 0 days & $100 \%$ & $95 \%$ & 28 \\
\hline & & & 3 days & $100 \%$ & $100 \%$ & 21 \\
\hline & & & 7 days & $100 \%$ & $95 \%$ & 31 \\
\hline
\end{tabular}

\subsubsection{Comparison between both methods}

On the one hand, the rolling bottle test was designed by Isacsson and Jorgensen (1987) in

Sweden, where the temperatures are significantly low. In that test, the samples are subjected for a long time to mechanical damage in the presence of water. This produced detachment of the weak mortar present on the surface of the recycled aggregates grains and, as a consequence, detachment of the bitumen coating as well. On the other hand, for the boiling water test, the samples are subjected to very high temperatures for a short period of time, not damaging the coating film mechanically but reducing the viscosity and consistency of the binder. Thus, this test would be more suitable to assess the performance of the mix in warm environments. As a consequence, the results are more affected by the performance of the recycled aggregates in the former test and by the binder in the latter.

In this case, the results of the boiling water test were very similar with both sorts of aggregate, whereas the performance in the rolling bottle tests was significantly poorer with CDWA than with NA. Hence, the results show that high temperatures will not significantly affect the binder- 
aggregate affinity of BSM-E with CDWA, but the prolonged action of traffic loads probably will. To assess this hypothesis, the long-term resistance to permanent deformation of these materials was evaluated and described throughout the next section.

\subsection{Resistance to permanent deformation}

\subsubsection{Initial creep strain $\left(\varepsilon_{0}\right)$}

The results of $\varepsilon_{0}$ are shown in Figure 8 for mixes with recycled aggregates and natural aggregates and are related to different water and bitumen contents. As seen, the strains reach a minimum value for $5 \%$ bitumen content in mixes with CDWA and $4 \%$ in mixes with NA.

However, the variation in water content produces wave-shaped trends with a minimum of $21 \%$ in mixes with CDWA and 9\% in mixes with NA.

It is important to highlight that the strains are lower when CDWA are used, not only for the optimal values but also for the other values in general. Thus, the recycled aggregates added a beneficial effect to the performance of the mix.
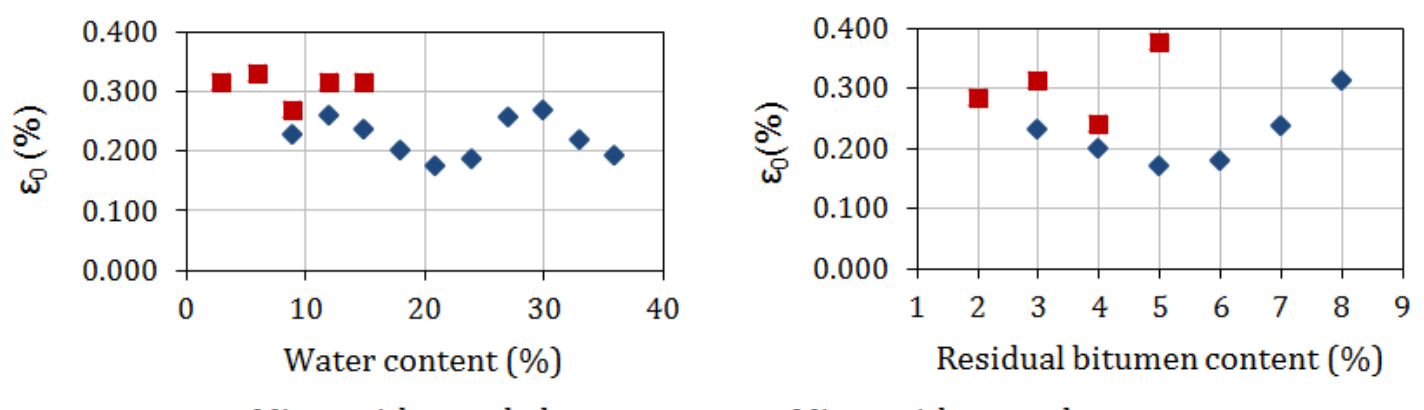

- Mixes with recycled aggregate

Mixes with natural aggregate

Figure 8. Initial creep strain after conditioning $\left(\varepsilon_{0}\right)$ for mixes with recycled and natural aggregate and for different water and bitumen contents

\subsubsection{Final creep strain $\left(\varepsilon_{5000}\right)$}

The results of $\varepsilon_{5000}$ are shown in Figure 9. As seen, the permanent deformation at the end of the test is simply similar with both types of aggregates. Thus, the addition of CDWA did not improve this parameter but also did not produce any detriment. Furthermore, by increasing water and/or bitumen contents, it is possible to obtain better performance with CDWA than with NA.

For both sorts of aggregates, the results tend to slightly decrease with increasing water and bitumen contents, not reaching clear optimal contents. 


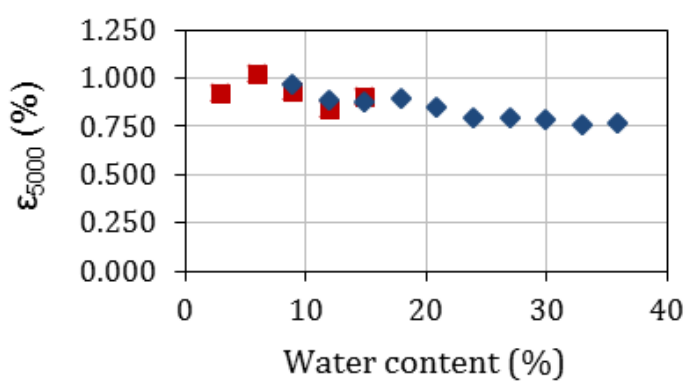

- Mixes with recycled aggregate

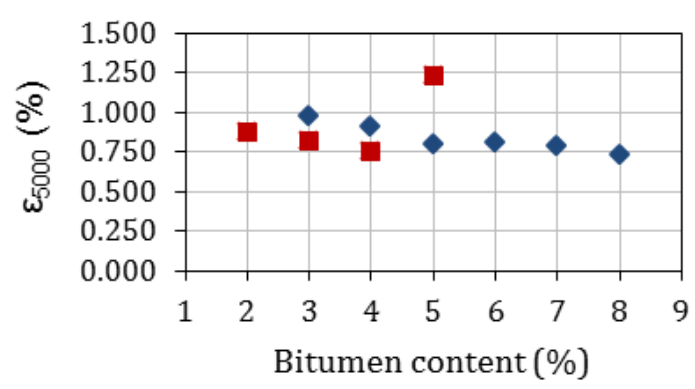

n Mixes with natural aggregate

Figure 9. Final creep strain after conditioning $\left(\varepsilon_{5000}\right)$ for mixes with recycled and natural aggregate and for different water and bitumen contents

\subsubsection{Slope of the tangent line in the secondary stage $(b)$}

The results are shown in Figure 10. As seen, the water content seems to not significantly affect the results, although peak values can be slightly intuited at approximately $24 \%$ content for mixes with CDWA and 6\% for mixes with NA. However, the increase in the bitumen content produces trends in the slopes similar to exponential curves, always increasing. Therefore, it would be advisable to design mixes with low bitumen content.

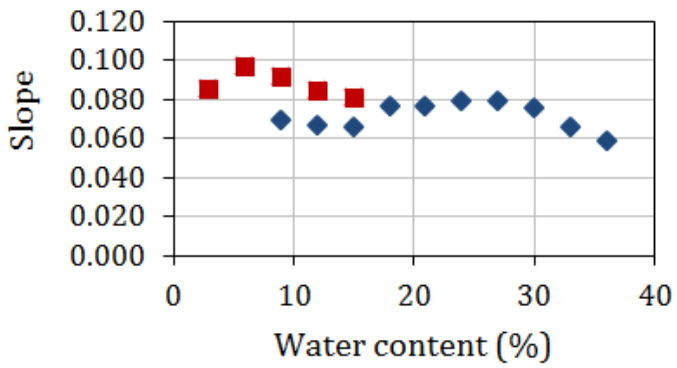

- Mixes with recycled aggregate

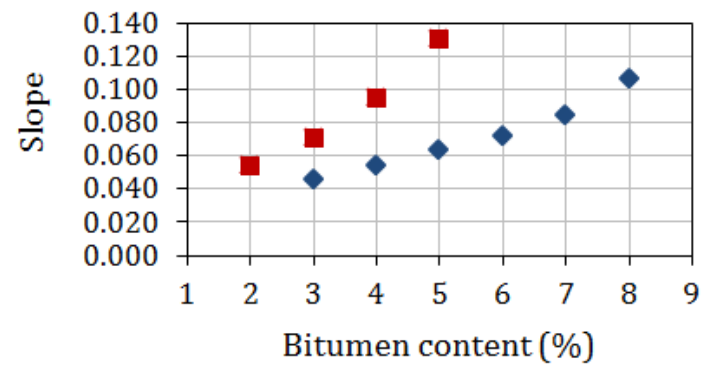

- Mixes with natural aggregate

Figure 10. Slope of the tangent line in the secondary stage (b) for mixes with recycled and natural aggregate and for different water and bitumen contents

In addition, mixes with CDWA generally show lower slopes than mixes with NA for any water or bitumen content. Thus, CDWA help mixes contain the development of permanent strains along the load cycles; in other words, mixes with CDWA are more stable and develop strains more slowly than mixes with NA.

\subsubsection{Cutting point of the tangent line with the vertical axis $(a)$}

The results of parameter $a$ are shown in Figure 11. As seen, for mixes with both sorts of aggregates, the parameter $a$ decreases with increasing water content until it reaches a minimum value, from which the results increase again. The optimal water content that produces the 
minimum a values are $30 \%$ for mixes with CDWA and $9 \%$ for mixes with NA. As in previous cases, owing to the high water absorption of the aggregates, the optimal water content is higher for mixes with CDWA. At the same time, the trends with the variation of bitumen content are decreasing (mixes with NA seem to present an optimal bitumen content of $4 \%$ ).

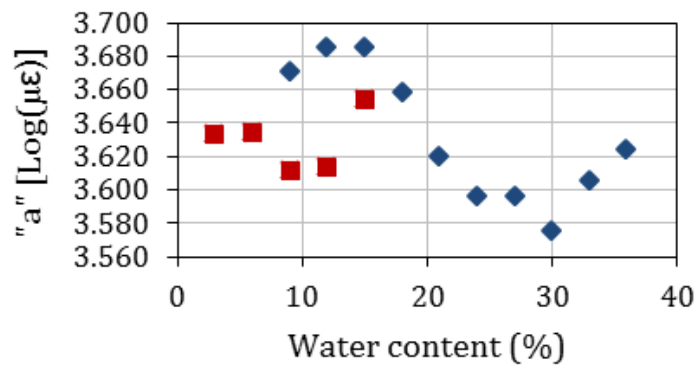

- Mixes with recycled aggregate

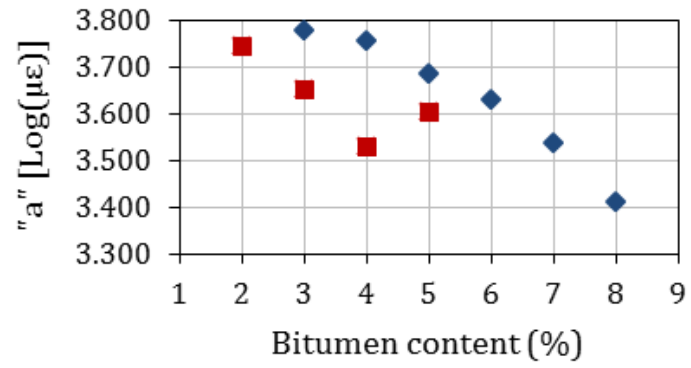

- Mixes with natural aggregate

\section{Figure 11. Cutting point of the tangent line with vertical axis (a) for mixes with recycled and natural aggregate and for different water and bitumen contents}

It can also be observed how the trends of parameter $a$ and slope $b$ are contrary; this makes perfectly sense considering that, as revealed previously, the deformations at the end of the test are similar. Thus, straight tangent lines passing by the same final point will intersect the vertical axis at higher values when their slopes are lower, and vice versa. Therefore, in this case, although mixes with CDWA tend to produce higher a-values (which would indicate poorer performance), this is simply due to the conjunction of same final strain and lower slope in the secondary stage. Because both aspects are positive, it can be concluded that CDWA improve the resistance to permanent deformation of BSM-E.

\subsubsection{Flow Number}

The Flow Number was not reached for any of the tested samples - not even when subjecting them to 10,000 cycles, the maximum programmable number of cycles for the available equipment (Cooper NU14). However, it was explained that because the deformation at the end of the test is practically the same for mixes with both sorts of aggregates and the slope of the curve during the secondary stage is lower for mixes with CDWA, the permanent deformation of these mixtures is more controlled and develops more slowly. This indirectly indicates that the tertiary stage will be reached after a greater number of loading cycles. Therefore, the Flow 
Number is expected to be higher.

\subsubsection{Comparison with other authors' results}

Although many authors have studied resistance to permanent deformation, the great range of variations in the test procedures complicate any comparison of the results here obtained with those obtained by the mentioned authors. However, it was found that Pasandín and Pérez (2013) used exactly the same test (although applying only 1800 load cycles) on samples of hot mix asphalt with up to $30 \%$ CDWA.

The creep strains obtained in the present investigation generally range from $0.6 \%$ to $0.8 \%$, slightly higher than those obtained by the referenced authors (normally ranging between $0.4 \%$ and $0.6 \%$. The resulting average slopes, as defined by the authors, were also higher, approximately $5 \cdot 10^{-5}\left[\% /\right.$ cycle] against approximately $3 \cdot 10^{-5}[\% /$ cycle $]$.

\subsection{Ecological analysis}

The requirement for slightly higher bitumen contents by weight of dry aggregate places graveemulsions with CDWA at an ecological and economic disadvantage. However, owing to the low specific weight of CDWA, for the same water and bitumen contents, the resulting density of the mixtures with recycled aggregate was 18-19\% lower (e.g., the specific weight of BSM-E with $4 \%$ residual bitumen and $9 \%$ water is $1.947 \mathrm{t} / \mathrm{m}^{3}$ with CDWA and $2.390 \mathrm{t} / \mathrm{m}^{3}$ with NA). Therefore, for the construction of the same unitary length of road, a smaller quantity (in weight) of mixture is needed. By making the corresponding calculations, it was found that by using BSM-E with CDWA and 5\% bitumen content, the extra amount of residual binder would be $1.1 \%$, and for lower binder contents, the use of CDWA would result in savings in bitumen costs. This, together with the evident economic and ecological benefits of using a byproduct as aggregate instead of exploiting a natural resource, makes these mixtures cleaner and more sustainable than current ones made with NA.

\section{Conclusions}

The present paper completed the investigation presented in previous publications in which the advantages of using CDWA in cold mixtures was stated not only in economic and ecological terms but also in terms of mechanical performance [Gómez-Meijide and Pérez 2014a, 2014b, 
2015; Gómez-Meijide et al., 2015a, 2015b; Pasandín et al., 2015]. From the present research, new findings were obtained and are described as follows:

1. Although the binder-aggregate affinity was practically the same for both aggregates when subjecting the mixtures to high temperatures, the weak mortar attached to the surface of recycled aggregates produced poorer results under mechanical agitation. Increasing the water content reduces the necessary mixing time for complete coating, but the results are still far from those obtained with NA.

2. Despite the previous conclusion, the use of CDWA improved the general performance of the mixes in terms of resistance to permanent deformation. The mixtures with both sorts of aggregates showed very similar deformations at the end of the tests, but in those mixtures made with CDWA, the deformations developed more slowly, which indirectly indicates that the tertiary stage and the consequent failure of the material will be reached after a greater number of loading cycles (higher Flow Number).

\section{Acknowledgments}

The authors would like to acknowledge the funding of project BIA2010-17751 and the scholarship FPI (ref. BES-2011-044377) by the Spanish Ministry of Economy and Competitiveness. The authors also would like to express their sincere gratitude to the GESTAN Group for the CDWA and to ECOASFALT for the bitumen emulsion that was generously donated for the present research.

\section{References}

ATEB (Technical Association of Bituminous Emulsions). Gravel-emulsion specifications. ATEB (consulted on-line in <http:// http://ateb.es/images/pdf/PLI_GRAVA.pdf > last time on 07/03/2016).

Bhusal, S., Wen, H., 2013. Evaluating recycled concrete aggregate as hot mix asphalt aggregate. Adv. Civ. Eng. Mater. 2(1), 262-265.

Bravo, M., Brito, J., Pontes, J., Evangelista, L., 2015. Mechanical performance of concrete made with aggregates from construction and demolition waste recycling plants. J. Clean. Prod. $99,59-74$ 
Chen, M.Z., Lin, J.T., Wu, S.P., 2011a. Potential of recycled fine aggregates powder as filler in asphalt mixture. Const. Build. Mater. 25, 3909-3914.

Chen, M.Z., Lin, J.T., Wu, S.P., Liu, C.H., 2011b. Utilization of recycled brick powder as alternative filler in asphalt mixture. Const. Build. Mater. 25, 1532-1536.

Gómez-Meijide, B., Pérez, I., 2014a. A proposed methodology for the global study of the mechanical properties of cold asphalt mixtures. Mater. Des. 57, 520-527.

Gómez-Meijide, B., Pérez, I., 2014b. Effects of the use of construction and demolition waste aggregates in cold asphalt mixtures. Constr. Build. Mater. 51, 267-277.

Gómez-Meijide, B., Pérez, I., 2015. Nonlinear elastic behavior of bitumen emulsion-stabilized materials with C\&D waste aggregates. Constr. Build. Mater. 98, 853-863.

Gómez-Meijide, B., Pérez, I., Airey, G., Thom, N., 2015a. Stiffness of cold asphalt mixtures with recycled aggregates from construction and demolition waste. Constr. Build. Mater. 77, $168-178$.

Gómez-Meijide, B., Pérez, I., Pasandín, A.R., 2015b. Recycled construction and demolition waste in Cold Asphalt Mixtures: evolutionary properties. J. Clean. Prod. 1-11.

Gul, W.A. 2008. Effect of recycled cement concrete content on rutting behavior of asphalt concrete. Doctoral Dissertation. Middle East Technical University. Ankara (Turkey).

HAUC (Highway Authority and Utility Committee), 1992. Specification for the reinstatement of opening in highways. new roads and street works. In: Act 1991. London. UK: HMSO.

Huang, W.L., Lin, D.H., Chang, N.B., Lin K.S. 2002. Recycling of construction and demolition waste via a mechanical sorting process. Resour. Conserv. Recycl. 37, 23-37.

Isacsson, W., Jorgensen, T. 1987. Laboratory methods for determination of the weather susceptibility of bitumen pavements. VIT report, Swedish Road Traffic Institute, No 324A.

James, A., 2006. Overview of asphalt emulsions. Asphalt emulsion technology, transportation research circular number E-C102. Washington DC (USA): Transportation Research Board. Jo, M.C., Tarrer A.R., Jeon Y.W., Park S.J., Yoon H.H., 1997. Investigation of the effect of aggregate pretreatment with antistripping agents on the asphalt-aggregate bond. Pet. Sci. Technol. 15, 245-271. 
Kiggundu, B.M., Roberts, F.L., 1988. Stripping in HMA mixtures: state-of-the-art and critical review of test methods. NCAT Report, 88-102.

Ledesma, E.F., Jiménez, J.R., Ayuso, J, Fernández, J.M., Brito, J., 2015. Maximum feasible use of recycled sand from construction and demolition waste for eco-mortar production - Part-I: ceramic masonry waste. J. Clean. Prod.87,692-706.

Li, J. 2004. Study on mechanical behavior of recycled aggregate concrete. Master thesis. Tongji University, Shanghai, China.

Melbouci., B., 2009. Compaction and shearing behavior study of recycled aggregates. Const. Build. Mater. 23, 2723-2730.

Mills-Beale, J., You, Z., 2010. The mechanical properties of asphalt mixtures with Recycled Concrete Aggregates. Const. Build. Mater. 24, 230-235.

Nageim, H., Al-Busaltan, S.F., Atherton, W., Sharples, G, 2012. A comparative study for improving the mechanical properties of cold bituminous emulsion mixtures with cement and waste materials. Constr. Build. Mater. 36, 743-748.

Paranavithana, S., Mohajerani, A. 2006. Effects of recycled concrete aggregates on properties of asphalt concrete. Resour. Conserv. Recycl. 48, 1-12.

Pasandín A.R., Pérez, I., 2014c. Mechanical properties of hot-mix asphalt made with recycled concrete aggregates coated with bitumen emulsion. Const. Build. Mater. 55, 350-358.

Pasandín, A.R., Pérez, I., 2013. Laboratory evaluation of hot-mix asphalt containing construction and demolition waste. Const. Build. Mater. 43, 497-505.

Pasandín, A.R., Pérez, I., 2014. Adhesion of recycled concrete aggregates, demolition debris and asphalt. Pet. Sci. Technol. 32, 2584-2591.

Pasandín, A.R., Pérez, I., Gómez-Meijide, B., Pérez-Barge, N., 2015. The effect of hydrated lime on the bond between asphalt and recycled concrete aggregates. Pet. Sci. Technol. 33, $1141-1148$.

Pérez, I., Gallego, J., Toledano, M., Taibo, J., 2010. Asphalt mixtures with construction and demolition debris. Inst. Civ. Eng. Proc. 163, 165-174. 
Pérez, I., Pasandín, A.R., Gallego, J., 2012. Stripping in hot mix asphalt produced by aggregates from construction and demolition waste. Waste Manage. Res. 30, 3-11.

Pérez, I., Pasandín, A.R., Medina, L., 2012. Hot mix asphalt using C\&D waste as coarse aggregates. Mater. Des. 36, 840-846.

Pérez, I., Toledano, M., Gallego, J., Taibo, J., 2007. Mechanical properties of hot mix asphalt made with recycled aggregates from reclaimed construction and demolition debris. Mater. Constr. 57, 17-29.

Read, J., Whiteoak, D., 2003. The shell bitumen handbook. London: Thomas Telford Publishing.

Rodríguez, C., Parra, C., Casado, G., Miñano, I., Albaladejo, F., Benito, F., Sánchez, I., 2016. The incorporation of construction and demolition wastes as recycled mixed aggregates in nonstructural concrete precast pieces. J. Clean. Prod. In Press, Accepted Manuscript, Available online 8 April 2016.

Saiz Martínez, P., González Cortina, M., Fernández Martínez, F., Rodríguez Sánchez, A., Comparative study of three types of fine recycled aggregates from construction and demolition waste (CDW), and their use in masonry mortar fabrication. J. Clean. Prod. 118,162-169.

Santagata, F.A., Canestrari, F., Pasquini, E., 2007. Mechanical characterization of asphalt rubber-wet process. Proceedings of 4th International SIIV Congress. Palermo, Italia.

Shen, D.H., Du, J.C. 2005. Application of gray relational analysis to evaluate HMA with reclaimed building materials. J Mater Civ. Eng. 17(4), 400-406.

Thanaya, I.N.A., 2003. Improving the performance of cold bituminous emulsion mixtures incorporating waste materials. Doctoral Dissertation, The University of Leeds. UK.

Thanaya, I.N.A., 2010. Utilization of sustainable materials in cold asphalt emulsion mixture for lightly trafficked road. The 6th International Student Conference at Ibaraki University ISCIU6. Japan. 
Vieira, C.S., Pereira, P.M., Lopes, M.L., 2016. Recycled Construction and Demolition Wastes as filling material for geosynthetic reinforced structures. Interface properties, J. Clean. Prod. In Press, Corrected Proof, Available online 8 March 2016.

Wong, Y.D., Sun, D.D., Lai, D., 2007. Value-added utilization of recycled concrete in hot-mix asphalt. Waste Manag. 27, 294-301.

Xuan, D.X., Molenaar, A.A.A., Houben, L.J.M., 2015. Evaluation of cement treatment of reclaimed construction and demolition waste as road bases. J. Clean. Prod. 100,77-83. 